\title{
A política na TV: o horário eleitoral da eleição presidencial de $1994^{1}$
}

\author{
Mauro Pereira Porto ${ }^{2}$ e Liziane Soares Guazina ${ }^{3}$ \\ Universidade de Brasília
}

\begin{abstract}
A propaganda política dos candidatos e partidos na televisão têm sido objeto de diversos estudos, muitos dos quais a definem como um elemento importante do processo político. Desde o estudo "clássico" sobre a eleição presidencial de 1972 nos Estados Unidos (Patterson \& McClure, 1976), tem predominado a noção de que a propaganda política contribui muito mais para a compreensão do processo político e eleitoral do que os telejornais. As pessoas entenderiam melhor a posição dos candidatos sobre as questões substantivas (os issues) através dos spots, enquanto os telejornais tendem a cobrir o processo político-eleitoral de forma trivial. Segundo esta perspectiva, o telejornalismo privilegia o aspecto da "corrida de cavalos" (horse race): o dia-a-dia da campanha, os eventos, comícios, pesquisas eleitorais, ganhadores e perdedores (p. 40-41). A "superioridade" da propaganda política da TV com relação aos noticiários tem sido, todavia, questionada. A pesquisa desenvolvida por Zhao e Chaffee (1995), por exemplo, chegou a conclusões opostas sobre a comparação entre telejornais e spots. Segundo os autores, os resultados deste e outros estudos serviram para "reabilitar a baixa reputação dos noticiários de TV em diversos círculos acadêmicos" (p. 54).
\end{abstract}

No Brasil, o interesse pelo Horário Eleitoral Gratuito (HEG) da televisão tem sido crescente, apesar de ainda serem poucos os estudos dedicados às relações entre televisão e processo político. Alguns autores discutiram a legislação sobre o acesso de candidatos e partidos aos mídia (Duarte, 1980; Vieira, 1993; Lima, 1994), as relações entre ética e propaganda politica (Gomes, 1994), as particularidades da propaganda 
televisiva no Brasil (Albuquerque, 1995a), as mudanças provocadas pelo marketing comercial (Miguel, 1997) ou analisaram o conteúdo da propaganda de partidos específicos (Del Valle, 1995).

No campo dos estudos dos "efeitos" do HEG no processo eleitoral, alguns autores buscaram comprovar o pouco peso destes programas na decisão do voto, ressaltando a debilidade da relação entre tempo dos partidos na TV e resultados eleitorais (Carneiro \& Schmitt, 1995) ou o impacto seletivo e, portanto, limitado, do Horário Eleitoral (Lima Jr., 1993). Outros estudos reconheceram o papel do horário eleitoral, apesar de indicar a importância de outras fontes de comunicação interpessoal, como familiares e amigos (Straubhaar et al., 1993). Estes trabalhos se caracterizam pela utilização de metodologias quantitativas, cujas limitações na análise dos efeitos dos mídia já foram apontadas (ver Bartels, 1993).

Este artigo tem por objetivo apresentar os resultados da análise de conteúdo dos programas do Horário Eleitoral Gratuito (HEG) televisivo da eleição presidencial de 1994, buscando identificar, através de uma metodologia que incorpore elementos quantitativos e qualitativos, os tipos de apelo apresentados pelos seis candidatos mais votados: Fernando Henrique Cardoso, Luís Inácio Lula da Silva, Enéas, Leonel Brizola, Orestes Quércia e Esperidião Amim ${ }^{1}$. Antes de passarmos à análise dos programas, discutiremos algumas das características do HEG da eleição presidencial de $1994 \mathrm{e}$ apresentaremos a metodologia utilizada.

\section{O HEG da Eleição Presidencial de 1994}

O Horário Eleitoral Gratuito das eleições de 1994 foi marcado por importantes mudanças na legislação que acabaram por gerar polêmica. A Lei 8.713 de 30 de setembro de 1993 proibiu imagens fora dos estúdios de gravação e as montagens com imagens. Para alguns autores, estas alterações tornaram os programas do HEG menos interessantes para os espectadores, reduzindo enormemente o seu potencial informativo (Albuquerque, 1995b; Miguel, 1997). Ainda que as alterações tenham restringido os recursos técnicos disponíveis aos candidatos e partidos, o papel do Horário Eleitoral não pode ser subestimado. Uma das evidências da importância destes programas são os seus índices de audiência. Os setores que defendem o fim do Horário Eleitoral Gratuito no rádio e na televisão têm utilizado como argumento os seus supostos baixos índices de audiência. Os dados referentes ao HEG da eleição presidencial de 
1994 demonstram que este argumento não tem fundamento. A média de audiência dos programas dos candidatos à Presidência em 1994 foi a seguinte, segundo o IBOPE:

Tabela 1 - Audiência do Horário Eleitoral dos candidatos à Presidência na eleição de 1994 em nove regiões metropolitanas (Média dos domicílios com TV ligados entre 20:30 e 21:00)

Região Metropolitana

Audiência

Porto Alegre

Rio de Janeiro

São Paulo

Florianópolis

Curitiba

Belo Horizonte

Recife

Salvador

Distrito Federal

Média de audiência nas 9 regiões
$39,5 \%$

$46,7 \%$

$46,8 \%$

$56,1 \%$

$56,4 \%$

$58,9 \%$

$63,7 \%$

$66,2 \%$

$70,4 \%$

$56,1 \%$

*Fonte: Relatório ADH (Audiência Domiciliar por Horário), IBOPE.

Os dados de audiência demonstram que uma média de 56,1\% dos domicílios permaneceram com seus televisores ligados durante os 34 dias de Horário Eleitoral da campanha presidencial entre $20 \mathrm{~h} 30$ e $21 \mathrm{~h}$ nas nove regiões metropolitanas. Esta média coloca o horário eleitoral dos candidatos à Presidência entre os programas diários de maior audiência da televisão brasileira, o "Jornal Nacional" e as telenovelas da Rede Globo. Não tem fundamento, portanto, o argumento de que a população não assiste aos programas ${ }^{2}$. Também o argumento de que a população rejeita o horário eleitoral é enganoso. Segundo pesquisa do DataFolha realizada em julho de 1994, 57\% do eleitorado é favorável à exibição do horário eleitoral (ver Jorge, 1995, p. 61).

\section{Metodologia da análise de conteúdo}

Quando os estudos sobre o Horário Eleitoral Gratuito de televisão se dedicam à análise de conteúdo dos programas, a tendência é a utilização de métodos exclusivamente quantitativos ou exclusivamente qualitati- 
vos, sendo poucos os trabalhos que buscam a integração de ambos. Fátima Carvalho (1994), por exemplo, desenvolveu uma complexa metodologia de codificação dos programas da eleição presidencial de 1989 que incluiu quatorze dimensões e 145 variáveis temáticas, adotando um enfoque quantitativo. Outros trabalhos adotaram métodos qualitativos na análise do conteúdo dos programas. Afonso de Albuquerque (1996), por exemplo, desenvolveu uma sofisticada análise dos programas da eleição presidencial de 1989 com base na teoria da construção social da realidade e na análise de enquadramentos (frame analysis). Karina Kuschnir (1995) e Vladimyr Jorge (1995) também optaram por uma análise qualitativa da propaganda política da televisão.

Estes estudos constituem importantes contribuições para a compreensão das características e funções do conteúdo da propaganda política televisiva. Entretanto, a ênfase exclusiva em metodologias quantitativas ou qualitativas tem sido criticada. No caso da análise de conteúdo quantitativa, a tendência é a ausência de um tratamento teórico adequado ao objeto de estudo ${ }^{3}$ e a sua descontextualização, além da negação do poder explanatório dos importantes procedimentos qualitativos de análise. Nas abordagens qualitativas, inexistem formas mais rigorosas e sistemáticas de coleta de dados, evitando-se questões como confiabilidade, validez e capacidade de generalização.

Alguns autores têm argumentado contra a posição freqüentemente adotada na análise de conteúdo dos programas televisivos de que enfoques quantitativos e qualitativos são mutualmente exclusivos (Stampel, 1981, p. 121). No presente estudo, buscaremos desenvolver um enfoque integrado que incorpore ambas perspectivas ${ }^{4}$. No caso da análise quantitativa, o objetivo é utilizar procedimentos sistemáticos que nos permitam obter uma visão de todo o conteúdo dos programas, e não apenas de elementos isolados, o que aumenta a capacidade de generalização dos dados. No caso da análise qualitativa de conteúdo dos meios de comunicação, o objetivo é entender não só "quais" temas foram tratados, mas "como" foram tratados, interpretando os significados e valores criados nos mídia (Christians \& Carey, 1981, pp. 346-347). Através de procedimentos qualitativos é possível identificar as estratégias simbólicas utilizadas pelos candidatos na interpretação dos temas.

A análise do Horário Eleitoral Gratuito da eleição presidencial de 1994 foi desenvolvida a partir de uma classificação dos tipos de "apelos" utilizados pelos candidatos em seus programas. O trabalho está ba- 
seado na tipologia elaborada por Richard A. Joslyn (1990) para a interpretação da propaganda política televisiva nos Estados Unidos. O objetivo do autor era o de identificar que tipos de entendimento e decisões são compatíveis e encorajados pela propaganda dos candidatos e partidos. O trabalho de Joslyn apresenta seis tipos principais de apelo: politicas futuras ("prospective policy choice appeals"), politicas passadas ("retrospective policy performance"), atributos pessoais ("benevolent leader appeals"), partisãos ("partisan appeals"), ideológicos ("ideological appeals") e simbólicos ("simbolic appeals"). Adicionamos a estes mais dois tipo de apelo e desenvolvemos a seguinte tipologia para a análise dos apelos dos candidatos no HEG da eleição presidencial brasileira de 1994:

1. Políticas Futuras (PF) - este apelo inclui as propostas ou planos de governo apresentados pelos candidatos em seus programas, sendo dividido em dois tipos: a) "gerais", quando as propostas são apresentadas de forma genérica e vaga, sem a especificação de como seriam implementadas, como, por exemplo, quando o candidato propõe acabar com a fome no país, mas não indica como essa promessa se realizaria; b) "específicas": quando as propostas ou planos de governo são apresentados de forma concreta, indicando as formas de sua implementação no futuro governo, como, por exemplo, quando o programa do candidato especifica o total de verbas que serão utilizadas na recuperação das estradas;

2. Políticas Passadas (PP) - apelo que remete ao que o candidato ou seu partido realizou no passado quando esteve no governo, seja na esfera municipal, estadual ou nacional;

3. Atributos Pessoais (AP) - apelo que ressalta as qualidades/características da pessoa do candidato, como, por exemplo, conhecimento, preparo, experiência, honestidade, etc. Inclui relatos sobre a biografia do candidato;

4. Partisão (PART) - apelo que vincula o candidato a partidos, personalidades, movimentos sociais, incluindo as manifestações de apoio à sua candidatura, como, por exemplo, a relação que os candidatos estabeleceram entre a sua pessoa e a campanha contra fome, a campanha das diretas, e personalidades como Juscelino Kubitschek;

5. Ideológico (IDEO) - apelo utilizado quando o programa relaciona a candidatura com categorias como esquerda/direita, socialista, liberal, conservador, progressista, nacionalista, etc.; 
6. Simbólico (SIMB) - apelo que remete a valores culturais, mitos, ideais, tais como estabilidade, união, otimismo, ética, solidariedade, pátria, etc.;

7. Análise de Conjuntura $(\mathrm{CONJ})$ - refere-se às mensagens que avaliam a situação do país, como, por exemplo, a taxa de desemprego, a saúde, educação, etc.. Entre os temas da conjuntura, o Plano Real ocupou uma posição central e importante nas eleições de 1994, constituindo o tipo principal de análise de conjuntura ${ }^{5}$. Através deste apelo, buscamos identificar a atitude dos candidatos com relação ao Plano. Sempre que o Real constituía o tema central da mensagem do programa, seja na forma de elogio, crítica ou avaliação, o apelo foi classificado nessa categoria;

8. Propaganda Negativa (PN) - apelo que busca criticar ou desqualificar outros candidatos, personalidades ou instituições. Este apelo foi subdividido em dois tipos principais: a) "críticas a outros candidatos": quando o candidato ou seu programa fazem acusações, cobranças ou denúncias sobre outros candidatos ou seus vices; b) "críticas às instituições políticas": quando se critica ou se desqualifica instituições/grupos como, por exemplo, partidos, classe política, governo, Congresso, etc.;

9. Outros - foram incluídos nesta categoria os segmentos que visam promover a campanha do candidato como, por exemplo: a divulgação de resultados de pesquisa, chamamentos para a participação em comícios, solicitações de contribuições financeiras, músicas compostas para a campanha (jingles), "vinhetas" que divulgam o nome do candidato, siglas partidárias ou slogans de campanha ${ }^{6}$. Por último, o apelo incluiu também mensagens diversas que não se enquadravam nos demais tipos de apelo, como, por exemplo: o tempo dedicado aos direitos de resposta concedidos pela justiça eleitoral, tempos não utilizados pelo partido ou cancelados pela justiça eleitoral, temas diversos que não se enquadravam nas demais categorias.

Com base nessa tipologia, o procedimento de análise foi o seguinte: a) classificamos a mensagem de acordo com um dos tipos de apelo ${ }^{7}$; b) cronometramos o tempo de cada apelo; c) transcrevemos o trecho completo ou suas partes principais em formulários padronizados organizados por programa e por candidato.

A pesquisa incluiu 33 dos 34 programas dos candidatos à Presidência que foram ao ar durante a veiculação do Horário Eleitoral Gra- 
tuito ( 3 de agosto a 30 de setembro de 1994) ${ }^{8}$. Os programas da campanha presidencial totalizavam 30 minutos de duração por dia e foram ao ar aos domingos, segundas, quartas e sextas, no horário das $20 \mathrm{~h} 30$ as $21 \mathrm{~h}^{9}$. A pesquisa incluiu, portanto, a classificação de um total de 16 horas e 30 minutos de HEG.

De acordo com a legislação, o tempo do programa no HEG de cada um dos seis candidatos analisados foi dividido da seguinte forma:

\section{Tabela 2 - Tempo do programa no Horário Eleitoral Gratuito dos seis primeiros colocados na eleição presidencial de 1994*}

Candidatos:

3 a $17 / 8 / 1994$

(9 programas)

7 min. e 49 seg.

3 min. e 31 seg.

$1 \mathrm{~min}$. e $08 \mathrm{seg}$.

$6 \mathrm{~min}$. e $15 \mathrm{seg}$.

2 min. e 34 seg.

4 min. e 00 seg.
$19 / 8$ a $30 / 9$

(23 programas)

$8 \mathrm{~min}$. e $10 \mathrm{seg}$.

3 min. e 45 seg.

$1 \mathrm{~min}$. e $16 \mathrm{seg}$.

$6 \mathrm{~min}$. e $30 \mathrm{seg}$.

2 min. e 45 seg.

4 min. e 12 seg.

* Os dados referem-se à média de tempo dos programas. A diferença de tempo nos dois períodos se deve à renúncia do candidato Flávio Rocha (PL), anunciada no seu programa do dia 10 de agosto. O tempo do seu programa só foi dividido com os demais candidatos a partir do dia 19 de agosto.

Fonte: Pesquisa do Núcleo de Estudos Sobre Midia e Politica (NEMP) da Universidade de Brasilia.

Apresentaremos a seguir o resultado da análise de conteúdo dos programas do Horário Eleitoral Gratuito dos seis candidatos mais votados na eleição presidencial de 1994.

\section{Os "Apelos" dos Candidatos}

a) Fernando Henrique Cardoso.

O Gráfico 1 apresenta o resultado da análise de 4 horas, 21 minutos e 30 segundos do programa do candidato Fernando Henrique Cardoso.

\section{Gráfico 1}

Apelos apresentados pelo programa do candidato Fernando Henrique Cardoso no Horário Eleitoral Gratuito 
da eleição presidencial de 1994

(Porcentagem do tempo total do programa)

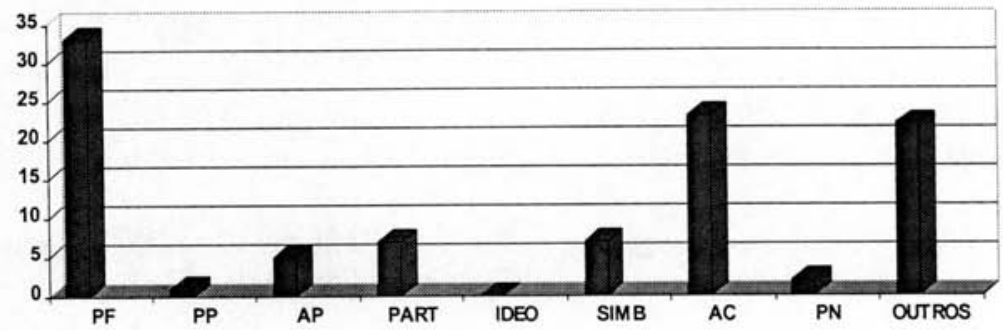

Fonte: Pesquisa do Núcleo de Estudos Sobre Midia e Política (NEMP) da Universidade de Brasilia.

O apelo mais utilizado por Fernando Henrique foi Políticas Futuras (PF), com $33 \%$ do tempo total de seu programa, divididos em $22 \%$ de propostas "gerais" e $11 \%$ de propostas "específicas". Isto demonstra que um elemento muito importante do seu programa foi a apresentação de propostas e de programas de governo considerados "viáveis", que "partem do que já existe". Os temas mais trabalhados nas propostas "gerais" foram as cinco metas de governo (emprego, saúde, educação, segurança e agricultura), incluindo a necessidade de acabar com o desemprego, melhorar a qualidade de ensino, acabar com a violência, incentivar a agricultura com irrigação, principalmente no Nordeste. Outras propostas apresentadas pelo candidato foram: acabar com as fraudes da Previdência; aumentar a arrecadação de impostos, combatendo a sonegação; acabar com a corrupção e a burocracia para aproveitar melhor as verbas que já existem; construir estradas; fazer a integração com o Mercosul; implantar o programa social Comunidade Solidária. Em "Políticas Futuras Específicas", o candidato se comprometeu a aumentar o salário mínimo para 140 Reais, gerar 3,5 milhões de empregos no campo com irrigação, reforma agrária e apoio às pequenas propriedades, municipalizar a saúde, integrar o país com a melhoria das estradas e ferrovias das regiões agrícolas, incentivar a criação de agroindústrias nas cidades pequenas, acabar de vez com a TR, garantir juros baixos para o crédito agrícola etc. 
Análise de Conjuntura (AC) foi o segundo apelo mais presente no programa do candidato, com $23 \%$ do total do seu tempo. Destes, $18 \%$ foram dedicados ao Real e $5 \%$ aos demais temas. Fernando Henrique vinculou diretamente sua candidatura ao Real, como criador do Plano e como o mais indicado para dar continuidade a ele. O Real foi definido como um plano "sério", "de verdade", que "devolveu respeito" e "levantou a moeda". No dia 11 de setembro, FHC afirma: "Eu criei o Real. Comecei sua implantação, defendo o Real desde o início". Em outra oportunidade, associa o Plano a valores como estabilidade e tranqüilidade, afirmando que "hoje é possivel planejar a vida sem os sobressaltos da inflação". A estabilidade econômica seria o primeiro passo para resolver os demais problemas durante o seu governo. O diagnóstico com relação ao Real foi o de que ele conseguiu derrubar a inflação, baixar os preços, aumentar o nível de emprego e derrotar a carestia. O candidato apresentou o índice de inflação medido pela FIPE, comemorando a sua queda para 1,95\% em setembro de 1994 . O povo estaria apoiando o Plano porque ele beneficia os mais pobres e por ter colocado "a casa em ordem". O Plano foi, portanto, um elemento central da sua estratégia de campanha. Nos 5\% restantes do apelo Análise de Conjuntura (AC), Fernando Henrique se dedicou principalmente a analisar a situação da falta de verbas na educação, do caos na saúde, do desemprego, da falta de incentivos à cultura, do rombo da Previdência, etc, buscando apresentar as causas destes problemas. No dia 28 de agosto, o candidato caracteriza o Brasil com um pais injusto: "enquanto milhões de famílias passam fome, o Brasil desperdiça boa parte do que produz". Estes apelos geralmente antecederam a apresentação de suas políticas futuras

Em terceiro e quarto lugar, empatados, estão os apelos Partisão (PART) e Simbólico (SIMB), com 7\% cada. Os aspectos simbólicos mais trabalhados pelo candidato foram: união, a "grande nação", otimismo, confiança no país, a valorização do povo ("gente em primeiro lugar"), prosperidade, estabilidade, orgulho de ser brasileiro. Com relação ao apelo Partisão (PART), dois terços do tempo do apelo foi dedicado à associação do candidato com personalidades, como Juscelino Kubitschek (a quem dedica um programa inteiro no dia 22 de agosto), Tancredo Neves, Ulisses Guimarães, Franco Montoro e Itamar Franco. $\mathrm{O}$ candidato associou-se ainda à campanha das diretas, às greves do $\mathrm{ABC}$ na década de 70 e à Campanha contra a Fome. Entre os apoios apresentados à sua candidatura, está a lista com 150 nomes de intelectu- 
ais e artistas, como, por exemplo, Jorge Amado, Dias Gomes, José Arthur Giannotti etc..

Em quinto lugar, com $5 \%$ do tempo total, está o apelo Atributos Pessoais (AP). Apesar do pouco tempo do apelo se comparado aos demais, é importante ressaltar que as características da personalidade do candidato foram muito reforçadas também pelos jingles. Entre os atributos apresentados, destacaríamos: competência, preparo, equilíbrio, liderança, firmeza, conhecimento, honestidade, seriedade, etc..

Finalmente, caberia ressaltar que o candidato dedicou pouco tempo do seu programa para o apelo Propaganda Negativa (PN), com $2 \%$ do tempo total do programa, que foram dedicado a criticar outros candidatos, principalmente Lula. Também praticamente não apresentou realizações anteriores, pois o apelo Políticas Passadas (PP) teve apenas $1 \%$ do tempo total. Além disso, o candidato não se identificou ideologicamente ( $0 \%$ para o apelo Ideológico).

$\mathrm{Na}$ categoria Outros, $15 \%$ do total de $22 \%$ foram dedicados aos jingles. Fernando Henrique foi o candidato que mais se utilizou dos jingles, não só em termos do tempo destinado a eles, mas também em termos da grande variedade de músicas apresentadas, em um total de 22. Os jingles foram um fator muito importante na campanha do candidato, ressaltando seus atributos pessoais, sua história de vida, seu programa de governo e trabalhando com diversos apelos simbólicos. As músicas contribuíram para a construção do clima de otimismo que caracterizou todo o programa, servindo também para vincular o candidato ao Plano Real ("nascido da firmeza de Fernando Henrique"), criticar os outros candidatos ("de que lado eles estão afinal? Uma hora dizem que gostam do Plano, outra hora atacam o nosso Real"), etc.. Nos demais $7 \%$ da categoria Outros, buscou-se divulgar a campanha do candidato, incluindo as vinhetas de abertura e fechamento do programa. Foram incluídos também avisos ensinando a população a votar no número do candidato e o "Jornal da Campanha", com um resumo da agenda de campanha.

b) Luís Inácio Lula da Silva

O Gráfico 2 apresenta o resultado da análise de 2 horas e 14 segundos do programa do candidato Luís Inácio Lula da Silva.

\section{Gráfico 2}


Apelos apresentados pelo programa do candidato

Luís Inacio Lula da Silva no Horário Eleitoral Gratuito

da eleição presidencial de 1994

(Porcentagem do tempo total do programa)

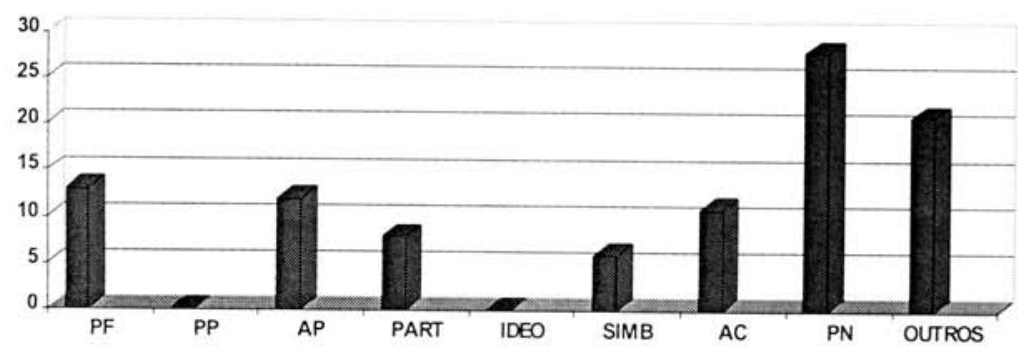

Fonte: Pesquisa do Núcleo de Estudos Sobre Midia e Politica (NEMP) da Universidade de Brasilia.

O principal apelo do candidato foi Propaganda Negativa (PN), com $28 \%$ do tempo total do programa. Destes, $23 \%$ foram dedicados a críticas a outros candidatos, dirigidas principalmente a Fernando Henrique e seu vice, Marco Maciel. Lula rotula FHC de candidato dos latifundiários, dos banqueiros, do governo, acusando-o de ser incoerente ("mudou de lado") e comparando-o a Collor. Portanto, a principal estratégia de sua campanha foi a tentativa de desmoralizar seu principal adversário. Nos $5 \%$ restantes deste apelo, o candidato criticou a incompetência e falta de ética do governo e seus dirigentes.

O segundo apelo mais freqüente no programa de Lula foi Políticas Futuras (PF), com 13\% do total. Destes, $9 \%$ foram dedicados a propostas gerais, onde o candidato manifestou preocupação com os temas da educação, saúde, emprego e reforma agrária, prometendo acabar com a inflação e a corrupção. Nos $4 \%$ restantes, o Lula apresentou propostas específicas, como no caso da reforma agrária, propondo a meta de beneficiar 800 mil famílias. Outras propostas foram: gerar 8 milhões de empregos em quatro anos, definindo as fontes dos recursos; investir em saneamento (água potável, coleta de lixo nas regiões carentes, etc); descentralizar o Sistema Único de Saúde, melhorando a formação dos profissionais da área, etc.. 
O terceiro apelo no programa de Lula foi Atributos Pessoais (AP), com $12 \%$. As principais características ressaltadas foram: sua origem popular, competência, coragem, coerência, capacidade e honestidade. Logo em seguida, em quarto lugar, está o apelo Análise de Conjuntura (AC), com $11 \%$. Destes, $8 \%$ foram dedicados ao Plano Real. Qual foi a atitude de Lula com relação ao Real? Buscamos responder a esta questão dividindo estes $8 \%$ dedicados ao Real em dois grupos principais: "crítica aberta", quando se combatia o Real como sendo um plano eleitoreiro, passageiro, que não beneficiava o povo, etc., e "crítica cautelosa", quando o programa reconhecia algum aspecto positivo do plano ou quando afirmava que o candidato daria continuidade a ele em seu governo. Dos $8 \%$ do programa de Lula dedicado ao Real, $82 \%$ correspondem a "crítica aberta" e $18 \%$, "crítica cautelosa", o que demonstra a atitude crítica do candidato com relação ao Plano.

Em quinto lugar, está o apelo Partisão (PART), com $8 \%$. Lula buscou se associar ao movimento sindical, principalmente à greve dos metalúrgicos, à Caravana da Cidadania, à campanha contra a fome, a setores dos evangélicos, às diretas já, e artistas da televisão, entre outros setores e movimentos sociais. Em seguida, com $6 \%$, está o apelo $\underline{\text { Sim- }}$ bólico (SIMB). Entre os aspectos simbólicos, vale destacar: ética, esperança, solidariedade, fraternidade, o "Brasil dos sỏnhos", justiça social.

A categoria Outros incluiu $21 \%$ do tempo total do candidato. Destes, $10 \%$ foram dedicados aos jingles. As músicas foram utilizadas para ressaltar os atributos pessoais do candidato, apresentado-o como a "chance do povo", um candidato que "conhece o Brasil da gente. Ninguém como ele andou por aqui". Também trataram dos aspectos simbólicos de "um país melhor de verdade", "liberdade será o meu país", "uma nova alvorada", etc. A divulgação da campanha ocupou outros $6 \%$, incluindo: as vinhetas de abertura e encerramento, a divulgação e crítica das pesquisas de intenção de voto, divulgação dos comícios e orientações para os eleitores sobre como votar. Nos demais $5 \%$, destacam-se os direitos de resposta concedidos nos dois últimos dias do HEG para que o candidato a vice na chapa de Fernando Henrique, Marco Maciel, respondesse a denúncias. $\mathrm{O}$ candidato não se definiu ideologicamente, nem apresentou seu desempenho em políticas passadas.

c) Enéas

O Gráfico 3 apresenta o resultado da análise de 40 minutos e 41 se- 
gundos do programa do candidato do PRONA.

\section{Gráfico 3}

Apelos apresentados pelo programa do candidato

Enéas no Horário Eleitoral Gratuito

da eleição presidencial de 1994

(Porcentagem do tempo total do programa)

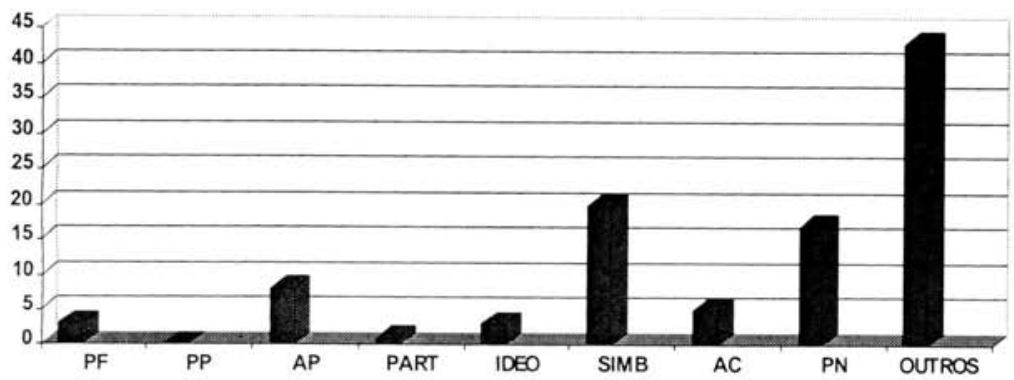

Fonte: Pesquisa do Núcleo de Estudos Sobre Midia e Politica (NEMP) da Universidade de Brasilia.

O apelo mais utilizado no programa de Enéas foi Simbólico (SIMB), com $20 \%$. Entre os valores a que o candidato buscou vincular-se, destacam-se: a imagem de "salvador da pátria", aquele que poderia defender a "nação espoliada" dos inimigos, da ameaça estrangeira; a idéia da "grande nação", da "nação abençoada" que deveria ser defendida.

Em segundo lugar, está o apelo Propaganda Negativa (PN), com $17 \%$. Destes, $9 \%$ foram dedicados à apresentação de críticas a outros candidatos. Enéas criticou principalmente o candidato Luís Inacio Lula da Silva, chamando-o de despreparado, ignorante, motivando um direito de resposta concedido pela justiça eleitoral ao candidato do PT. Enéas criticou também Fernando Henrique acusando-o de ser um candidato "do sistema" e "oficial". Do tempo total de críticas a outros candidatos, $70 \%$ foram dedicados a criticar Lula e Fernando Henrique conjuntamente e $30 \%$ a atacar somente o candidato Lula. Nos $8 \%$ restantes do apelo, o candidato criticou as instituições políticas. O candidato critica os políticos profissionais, integrantes de uma classe "podre", classificando-os como figuras "repugnantes", "mentirosas", "cínicas" e "hipócritas". 
Enéas criticou ainda a política de "troca de favores", afirmando que ela poderia ser feita de forma diferente.

Em terceiro lugar, aparece o apelo Atributos Pessoais (AP), com 8\%. Entre as qualidades do candidato ressaltadas pelo seu programa, estão: conhecimento (o único candidato que "tem conteúdo"), preparo, competência, capacidade, coragem, força, etc. O candidato do PRONA buscou destacar-se dos demais, apresentando-se como outsider, alguém que vem de fora da classe política.

Em seguida, está o apelo Análise de Conjuntura (AC), com 5\%. Destes, $3 \%$ foram dedicados à seca do nordeste e ao caos na saúde e $2 \%$ ao Plano Real, definido como um plano que teria um "falso valor". Empatados em quinto lugar, com $3 \%$, estão os apelos Ideológico (IDEO) e Políticas Futuras (PF). No plano ideológico, Enéas se definiu como um nacionalista que defende um "Estado forte", criticando tanto o neoliberalismo como o pensamento de esquerda. Em Políticas Futuras, o candidato tratou apenas de aspectos gerais, afirmando que iria resolver os problemas na área de saúde através de um "grande projeto nacional" (sem especificar as medidas a serem adotadas e como elas seriam implementadas), solucionar o problema da seca no Nordeste e defender a família brasileira dos meios de comunicação de massa.

Por último, com $1 \%$ do tempo total do programa, o apelo Partisão (PART), ressaltou o fato de Enéas ser o candidato do PRONA. No que se refere ao grande número de mensagens classificadas na categoria Outros $(43 \%)$, isto se deve, principalmente, ao grande tempo dedicado para a divulgação de sua campanha (28\%), quando o candidato: divulgou um livro de sua autoria, que seria o seu "grande projeto nacional"; apresentou dados de pesquisas eleitorais, mostrando o seu bom desempenho ou denunciando sua manipulação. Com relação a este último aspecto, o candidato mostrou uma carta de uma eleitora que afirmava ter sido procurada por um instituto de pesquisa e que o PRONA não constava da lista apresentada para a indicação do partido com o qual ela mais se identificava. Os demais $15 \%$ da categoria Outros se devem, principalmente, aos direitos de resposta que a Justiça Eleitoral concedeu ao candidato Luís Inácio Lula da Silva.

d) Oréstes Quércia

O Gráfico 4 apresenta o resultado da análise de 3 horas, 25 minutos e 8 segundos do programa do candidato do PMDB. 


\section{Gráfico 4 \\ Apelos apresentados pelo programa do candidato \\ Quércia no Horário Eleitoral Gratuito \\ da eleição presidencial de 1994}

(Porcentagem do tempo total do programa)

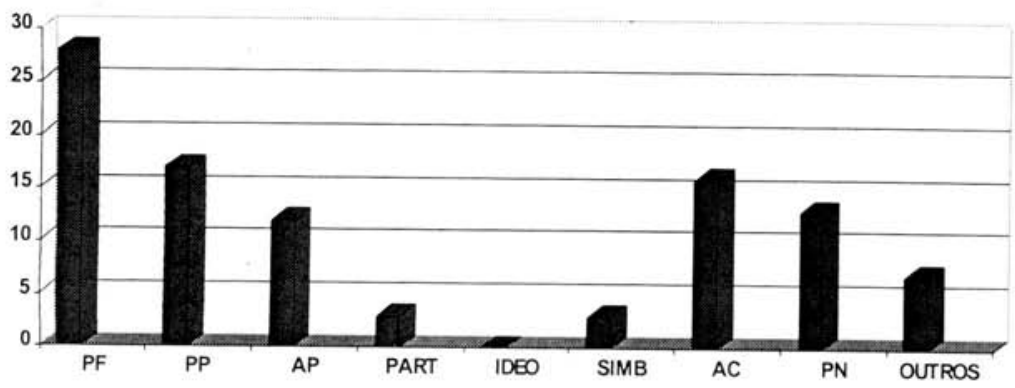

Fonte: Pesquisa do Núcleo de Estudos Sobre Midia e Politica (NEMP) da Universidade de Brasilia.

Em primeiro lugar no programa do candidato do PMDB, Oréstes Quércia, aparece o apelo Políticas Futuras (PF), com 28\%. Deste total, $16 \%$ foram dedicados a propostas específicas, quando o candidato apresentou um cronograma de atividades que implementaria caso fosse eleito que inclui: dividir o Brasil em 90 regiões de desenvolvimento para que os Estados possam definir prioridades para os investimentos; municipalizar a saúde e o ensino básico; aumentar de $18 \%$ para $25 \%$ os recursos do Orçamento da União destinados à Educação; manter 12 mithões de crianças pobre o dia inteiro na escola; criar corredores nacionais de transporte; financiar a agricultura para produzir 100 milhões de toneladas de grãos etc.. Os $12 \%$ restantes deste apelo foram dedicados a propostas gerais, apresentando-se como prioridade as áreas da educação, saúde, transporte, segurança e agricultura, sem, todavia, especificar como seriam tratadas.

Em segundo lugar aparece Políticas Passadas (PP), com 17\%. O candidato apresentou as suas realizações passadas como prefeito de Campinas e governador de São Paulo. Os seus governos anteriores teriam sido caracterizados por "grandes obras no interesse do povo", citando a cons- 
trução de estradas, hidrovias, e do Memorial da América Latina, a criação de um plano de habitação popular e da secretaria do menor que retirou 200 mil crianças das ruas de São Paulo, etc..

No terceiro lugar, com $16 \%$, está o apelo Análise de Conjuntura (AC). A quase totalidade do tempo deste apelo (14\%) foi dedicada à análise do Plano Real. Quércia criticou fortemente o Plano Real, acusando-o de ser um plano eleitoreiro que só funcionaria até as eleições, comparando-o ao Plano Cruzado. O candidato questiona as taxas que indicavam uma queda da inflação, afirmando que a caderneta de poupança renderá menos, não havendo correção monetária nem reajuste automático de salários, o que prejudica a população. Entretanto, as críticas do candidato do PMDB estão mais direcionadas à implementação do Plano por um governo fraco, que não controla os preços e não combate os especuladores, do que ao Plano em si. Nos poucos segmentos em que apoiou o Plano, Quércia apresenta a moeda forte como pré-requisito para a implementação do seu plano de governo. $\mathrm{O}$ candidato sugere que o Plano está em perigo devido ao governo fraco e que ele fará com que as conquistas do Real venham em benefício não só dos ricos, mas da população e do trabalhador. Nos $2 \%$ restantes do apelo, o candidato afirma que o país está paralisado, havendo uma "inversão" na educação, porque os ricos têm acesso a escolas melhores e os mais pobres só têm a alternativa da escola pública que tem um nível de ensino bem inferior. Quércia afirma que a questão da saúde pública é uma das mais sérias do país, "uma violência contra o trabalhador", e critica a distância entre ricos e pobres.

O apelo Propaganda Negativa (PN) aparece em quarto lugar, com $13 \%$. Deste total, $9 \%$ foram dedicados a criticar o candidato que liderava as pesquisas, Fernando Henrique, acusando-o de ser um candidato governista, representante dos ricos e dos empresários, um fraco, mentiroso que só promete e não cumpre. Quércia utiliza imagens do programa do candidato do PSDB para ironizar suas posições e apresentar suas próprias soluções como as melhores. Nos demais $4 \%$ do tempo do apelo o candidato criticou as instituições políticas, principalmente o governo, acusado de fraco e incompetente.

Em quinto lugar, com 12\%, o apelo Atributos Pessoais (AP) mostrou a imagem de um candidato experiente, realizador, bom administrador, competente, trabalhador e com muita força de vontade para fazer o que quer no governo. $\mathrm{O}$ candidato ressalta a sua origem popular e a sua tra- 
jetória até tornar-se um empresário. Busca-se assim vincular o candidato à imagem de competência e experiência que está fundamentada no seu passado e nas suas características pessoais.

Empatados em sexto lugar, com 3\%, estão os apelos Partisão (PART) e

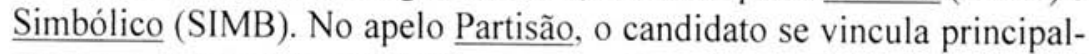
mente ao seu partido, o PMDB, e aos movimentos municipalista, sindical e dos aposentados. No apelo Simbólico, Quércia fala da união, que o Brasil é um país com um potencial extraordinário, que tem um povo trabalhador e que pode ter um futuro melhor.

Por último, a categoria Outros ocupou 7\% do tempo total do programa. Destes, $4 \%$ foram dedicados para a campanha do candidato, sendo utilizados para divulgar comícios e desmentir os resultados das pesquisas. Quércia afirma então que mais de $50 \%$ das pessoas estariam indecisas com medo de repetir o que aconteceu em 89 "com o outro Fernando". Os demais 3\% foram dedicados aos jingles. O apelo Ideológico (IDEO) não aparece no programa do candidato.

e) Leonel Brizola

O Gráfico 5 (na página seguinte) apresenta o resultado da análise de 1 hora, 28 minutos e 30 segundos do programa do candidato do PDT.

A grande ênfase na Propaganda Negativa (PN), com $29 \%$ do tempo total do programa, revela que a estratégia principal do candidato Leonel Brizola foi criticar os demais candidatos e as instituições políticas. Deste total, a maior parte do tempo $(27 \%)$ foi dedicada às críticas aos demais candidatos. Os principais alvos das críticas foram Fernando Henrique e Lula, com $52 \%$ e $12 \%$ do tempo total de críticas aos candidatos, respectivamente. Os dois candidatos foram alvos também de críticas simultâneas (31\%). Brizola definiu Fernando Henrique como o candidato da Rede Globo, da mídia e das pesquisas, um "instrumento do sistema", um político que renegou o seu passado. Lula foi definido como fraco, inexperiente, "marcado para perder" e incapaz. Nos $2 \%$ restantes do apelo, o candidato criticou as instituições políticas. O alvo principal foi o governo federal, considerado um governo fraco, sem unidade, sem apoio, sem visão e sem pulso. Também o Congresso é criticado pelo seu "gigantismo", devendo funcionar com metade dos deputados atuais, e o governo do Estado do Rio de Janeiro, devido à intervenção das Forças Armadas nas favelas 


\section{Gráfico 5 \\ Apelos apresentados pelo programa do candidato \\ Brizola no Horário Eleitoral Gratuito \\ da eleição presidencial de 1994 \\ (Porcentagem do tempo total do programa)}

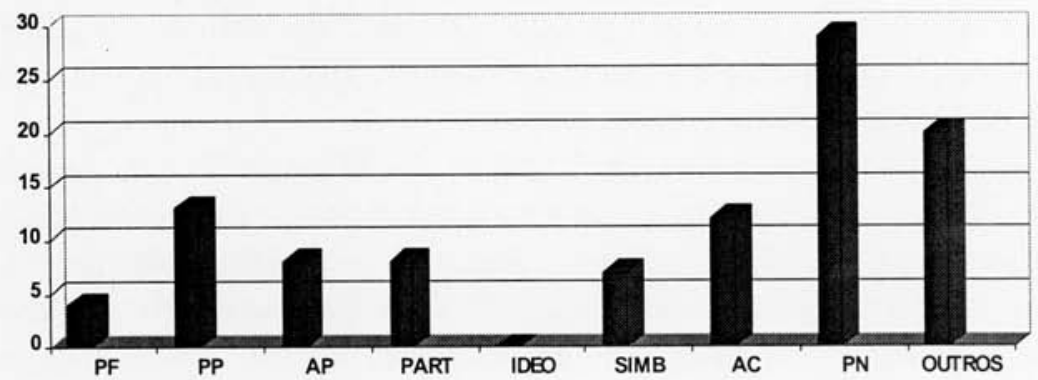

Fonte: Pesquisa do Núcleo de Estudos Sobre Midia e Politica (NEMP) da Universidade de Brasilia.

Em segundo lugar, com 13\%, o apelo Políticas Passadas (PP) apresentou as realizações do candidato quando governador do Rio Grande do Sul e do Rio de Janeiro. O programa apresenta a reforma agrária feita no Rio Grande do Sul, a construção de rodovias e, principalmente, a sua atuação na área da educação com a implementação dos CIEPS, "uma escola moderna e de tempo integral".

$\mathrm{O}$ apelo Análise de Conjuntura $(\mathrm{AC})$ aparece em terceiro lugar, com $12 \%$. A quase totalidade do tempo do apelo (11\%) foi dedicada ao Plano Real. O Real foi criticado fortemente pelo candidato, como no dia 7 de agosto, quando Brizola afirma: "A cada dia cresce o meu sentimento de revolta e indignação. Quem não vê que este Plano Real é uma nova armadilha só para ganhar as eleições, tal como ocorreu com Sarney e seu Plano Cruzado?". No tempo restante do apelo ( $1 \%)$, o tema foi a questão da educação.

Empatados em quarto lugar, com $8 \%$, estão os apelos Atributos Pessoais (AP) e Partisão (PART). Com relação aos atributos, o candidato é mostrado como um político experiente, honesto, coerente em seus prin-

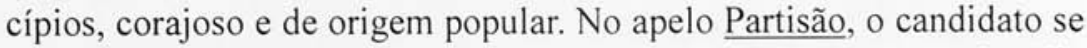
identifica com personalidades da política brasileira como Getúlio 
Vargas e João Goulart e grandes líderes como De Gaulle e Mitterrand, associando-se a minorias e setores como jovens, negros e bancários. Além disso, manifestou apoio aos candidatos do PDT ao governo dos estados.

Em sexto lugar, com 7\%, o apelo Simbólico (SIMB) trabalhou com valores como: a união nacional, um meio para superar as dificuldades e "passar o país a limpo"; a idéia de pátria que pode ter um futuro melhor. Em seguida, com 4\%, o apelo Políticas Futuras (PF), apresentou propostas gerais. Brizola afirmou que iria acabar com a exploração internacional, dar educação para todos, equipar a polícia, melhorar a atuação da justiça, etc..

A categoria Outros ocupou $20 \%$ do tempo total do programa de Brizola. Destes, $16 \%$ foram dedicados à campanha, quando as pesquisas são criticadas e se divulgam eventos de campanha. Apenas $1 \%$ do tempo total do programa foi dedicado aos jingles. $\mathrm{O}$ candidato não se definiu ideologicamente.

f) Esperidião Amim

O Gráfico 6 (na página seguinte) apresenta o resultado da análise de 2 horas, 14 minutos e 53 segundos do programa do candidato do PPB.

Os apelos com maior presença no programa de Amim foram Politicas Futuras (PF) e Políticas Passadas (PP), com 18\% cada. Em Políticas Futuras, $13 \%$ foram dedicados a propostas gerais e $5 \%$ a propostas específicas. Neste apelo, o candidato apresenta seus planos nacionais de educação, saúde, de combate ao desemprego, habitação. Afirmou ainda que iria criar incentivos aos microempresários, incluir os excluídos, dar uma atenção especial aos "pequenos". De forma mais específica, o candidato afirma: que os profissionais da educação não ganharão menos de um salário mínimo; que ele irá definir o papel das prefeituras, associações de médicos, faculdades de medicina para garantir uma administração eficiente dos hospitais; que investirá no turismo como alternativa de desenvolvimento da região Nordeste. Em Políticas Passadas, o candidato apresenta as suas realizações durante o período em que foi governador do Estado de Santa Catarina: os programas dedicados às crianças (Pró-Criança e PAIS), a criação de escolas, o incentivo ao esporte, a realização de uma verdadeira reforma agrária, o financiamento para pequenos agricultores, o apoio aos pequenos negócios para a geração de empregos. 


\section{Gráfico 6 \\ Apelos apresentados pelo programa do candidato \\ Amim no Horário Eleitoral Gratuito \\ da eleição presidencial de 1994 \\ (Porcentagem do tempo total do programa)}

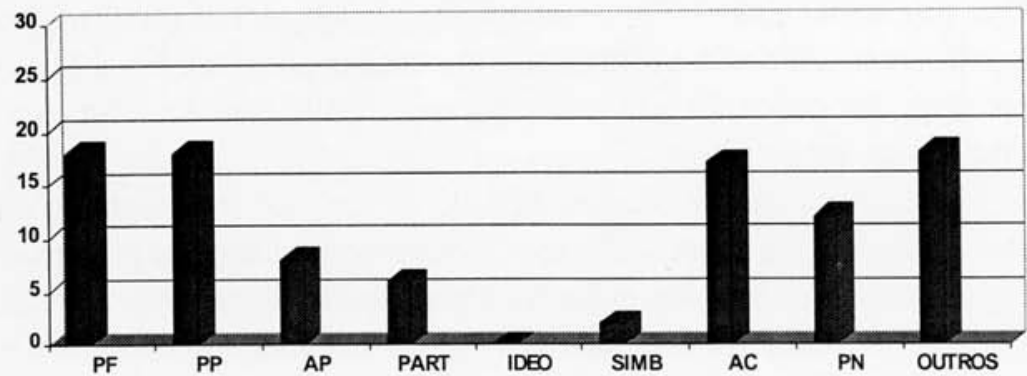

Fonte: Pesquisa do Núcleo de Estudos Sobre Midia e Politica (NEMP) da Universidade de Brasilia.

Em terceiro lugar, com $17 \%$ do tempo do programa do candidato, aparece o apelo Análise de Conjuntura (AC), sendo $9 \%$ dedicados ao Plano Real. Deste tempo dedicado ao Real, metade (50,78\%) foi dedicada a apoiar o Plano e a outra metade $(49,22 \%)$ a criticá-lo. Em suas críticas, Amim compara o Plano Real aos outros planos econômicos ("em apenas oito anos, sete planos, quase um plano por ano") e critica a associação do plano ao candidato Fernando Henrique ("o que nós não podemos admitir é que o Real seja usado com fins escancaradamente eleitoreiros"). O programa apresenta denúncias da imprensa sobre o uso eleitoral do plano. Por outro lado, o candidato também reconhece aspectos positivos do plano. Amim afirma que, se depender dele, o Real "veio para ficar" e que ele é a pessoa certa para implementar o plano: tem determinação, não tem compromissos com os sócios da inflação, sabe como funciona a engrenagem política e administrativa do país e tem a visão necessária para entender e solucionar os problemas nacionais. O candidato apóia o plano de forma explícita em diversos programas, como no dia 29 de agosto: "Tenho absoluta convicção de que no meu governo o Real será a nossa moeda para sempre e o Brasil será um 
país sem inflação, com mais riqueza e com mais donos dessa riqueza". Nos demais $8 \%$ do tempo deste apelo, o candidato faz uma análise da situação das crianças, da educação, da falta de emprego, dos baixos salários, ressalta a importância do turismo, etc..

Propaganda Negativa (PN) aparece em quarto lugar, com $12 \%$ do tempo total do programa do candidato. Destes, $10 \%$ foram dedicados a criticar outros candidatos. Com relação a Fernando Henrique, o candidato do PSDB é responsabilizado pela mortalidade infantil no Nordeste. O dinheiro destinado à saúde teria sido desviado por ele, quando Ministro da Fazenda no governo de Itamar Franco, para pagar o lucro de quem aplica no mercado financeiro. Amim cita dados da revista Veja para comprovar esta denúncia, acusando Fernando Henrique de ser o candidato do governo e que poderia ter solucionado os problemas do país quando estava no governo. Com relação a Lula, suas propostas de governo são criticadas. Amim afirma que a proposta de criação de oito milhões de empregos em quatro anos é inviável, que o governo não tem dinheiro para "assinar oito milhões de carteiras de trabalho. Você já imaginou oito milhões de funcionários públicos? E dinheiro estrangeiro ou dinheiro brasileiro que está lá fora, que é o que pode criar mais empregos, isso eles dizem que vão tratar como inimigo". Existem também críticas simultâneas a Fernando Henrique e Lula, quando se afirma que ambos não possuem experiência: "falar sobre reforma agrária, todo mundo fala, mas muito poucos têm experiência de fazer" (aparecem então fotos de Fernando Henrique e Lula com a frase: "nunca fez"). Nos $2 \%$ restantes, critica-se o governo, principalmente sua política agrícola, incluindo a TR e os juros altos.

Atributos Pessoais (AP) está em quarto lugar, com $8 \%$. Os principais atributos apresentados foram a experiência ("aprendeu fazendo"), a competência, a seriedade ("leva a política a sério"), juventude ("representa a nova geração") e honestidade. Em seguida, com 6\%, aparece o apelo Partisão (PART). Amim procurou vincular-se a Paulo Maluf, ao PPR ("a legenda de Maluf), a Jarbas Passarinho ("modelo de bom politico"), ao movimento pela revisão constitucional, às diretas-já (o primeiro governador a apoiar o movimento). Finalmente, com $2 \%$, está o apelo Simbólico (SIMB), com 2\%, quando o candidato exalta o povo (a sua capacidade de luta, garra, o seu caráter heróico e sua união) e o país, principalmente a capacidade de vencer. $\mathrm{O}$ candidato não se definiu ideologicamente e a categoria Outros ocupou 12\% do tempo do programa, 
sendo $10 \%$ dedicados aos jingles e $2 \%$ a agradecimentos.

\section{Conclusões}

Uma visão geral do conteúdo dos programas televisivos dos candidatos à Presidência na eleição de 1994 nos permite identificar os tipos de entendimento e decisões que foram compatíveis e encorajadas pela propaganda dos candidatos na eleição presidencial de 1994. O Gráfico 7 apresenta os dados agregados sobre os programas dos seis candidatos mais votados, totalizando 16 horas e 30 minutos.

\section{Gráfico 7}

Apelos apresentados no Horário Eleitoral Gratuito pelos programas dos seis candidatos mais votados na eleição presidencial de 1994

(Porcentagem do tempo total dos programas)

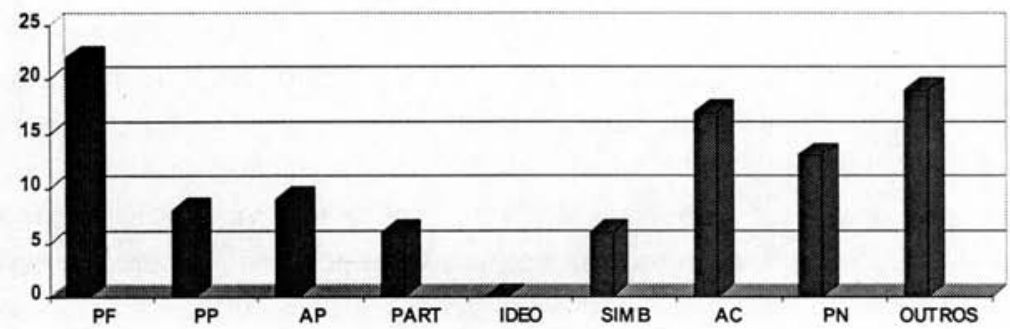

Fonte: Pesquisa do Núcleo de Estudos Sobre Midia e Politica (NEMP) da Universidade de Brasilia.

Os dados demonstram que Políticas Futuras (PF) foi o apelo mais freqüente com $22 \%$ do tempo total dos programas. A apresentação dos programas de governo ocupou uma posição importante na campanha presidencial de 1994. Portanto, o horário eleitoral incentivou os eleitores a julgar os candidatos em termos das suas propostas de governo, colocando este critério como um elemento importante do processo de decisão do voto. Fernando Henrique foi o responsável pela maior parte deste tempo, seguido de Quércia e Amim. Os candidatos Lula, Brizola e Enéas foram os que menos se dedicaram a apresentar os seus planos de governo. 
O segundo apelo com maior presença nos programas foi Análise de Conjuntura (AC), com 17\% do tempo total. A campanha eleitoral na televisão se apresentou aos eleitores também como uma disputa entre diferentes diagnósticos da situação do país. Entre os temas discutidos, o Plano Real ocupou o lugar mais importante. Os eleitores foram estimulados, portanto, a julgar os candidatos em termos de suas visões sobre os problemas nacionais, com especial ênfase no novo plano econômico. No que se refere aos diferentes candidatos, o padrão se repete: Fernando Henrique foi o responsável pela maior parte do tempo do apelo, seguido de Amim e Quércia. Os candidatos Lula, Brizola e Enéas foram os que menos se utilizaram deste tipo de apelo.

Em seguida, com 13\% do tempo total dos programas, aparece o apelo Propaganda Negativa (PN). A crítica a outros candidatos e às instituições políticas também teve uma presença importante no horário eleitoral. Todavia, neste caso, o padrão é oposto ao dos apelos anteriores. No caso da propaganda negativa, Brizola e Lula foram os que mais se utilizaram do apelo, seguidos de Enéas, Quércia e Amim. Fernando Henrique foi o que menos criticou outros candidatos ou instituições.

A propaganda política da televisão é um elemento central das campanhas eleitorais no mundo contemporâneo, mas ainda são poucos os estudos sobre o processo político e de decisão do voto que incluem modelos teóricos e metodológicos para a análise do seu conteúdo e de seus efeitos. A presente pesquisa tem por objetivo contribuir no debate sobre as alternativas teóricas e metodológicas disponíveis para o estudo do horário eleitoral da TV. Nesse sentido, é importante ressaltar que a propaganda televisiva não se desenvolve de forma isolada, devendo-se considerar o contexto mais amplo do processo político-eleitoral. Em particular, seria importante considerar a relação entre o horário eleitoral e o cenário de representação da política (CR-P) construído a longo prazo nos e pelos mídia, principalmente nos programas de maior audiência da televisão (Lima, 1994b, 1996). Alguns autores têm ressaltado a necessidade de se relacionar a propaganda política da TV, que se desenvolve no período de curto prazo que antecede as eleições, com o cenário construído a longo prazo pelos mídia (Soares, 1996; Almeida, 1997). Este tipo de análise em muito contribuiria para o nosso entendimento acerca do horário eleitoral da TV e seu papel no processo político e eleitoral.

À guisa de conclusão, apresentaremos uma análise da relação en- 
tre os apelos apresentados pelos candidatos na propaganda política da televisão na eleição presidencial de 1994 e o cenário construído a longo prazo nos programas de maior audiência da televisão. Pesquisas realizadas pelo Núcleo de Estudos Sobre Mídia e Política (NEMP) da Universidade de Brasília sobre o "Jornal Nacional" (Fabrício \& Maciel, 1994) e sobre as telenovelas da Rede Globo (Melo \& Oliveira, 1994; Porto, $1995)$ identificaram os elementos constitutivos do cenário de representação da Política (CR-P) nos marcos dos qual se desenvolveu a disputa eleitoral. Entre estes elementos, podemos destacar: a construção de um clima de otimismo e confiança; a cobertura favorável ao Plano Real e sua vinculação à pessoa de Fernando Henrique; a desqualificação da política e suas instituições; a desqualificação dos ideais e líderes da esquerda; a ênfase na importância do candidato ser bem preparado etc.. A hipótese sobre o processo eleitoral relacionada ao conceito de cenário de representação da política (CR-P) afirma que o candidato que melhor se adapta ao cenário tende a obter êxito, principalmente nas eleições majoritárias e nacionais (Lima, 1994b, 1996). Como se posicionaram os candidatos no horário eleitoral com relação a este cenário?

A análise de conteúdo dos programas do Horário Eleitoral revelou peculiaridades importantes sobre as estratégias dos candidatos à Presidência. É possível identificar uma estratégia muito semelhante dos candidatos de "centro-direita", Quércia e Amim (vide gráficos 4 e 6), com uma ênfase nas políticas futuras e passadas, bem como na análise de conjuntura e propaganda negativa. No caso dos candidatos de "centroesquerda" Lula e Brizola, também existem semelhanças importantes (vide gráficos 2 e 5). Em ambos os casos, a grande ênfase esteve na propaganda negativa, principalmente em atacar o candidato Fernando Henrique. Os gráficos dos dois candidatos são muito semelhantes, estando a diferença mais importante no fato de que Brizola apresentou suas realizações em governos anteriores e Lula não apresentou nenhum apelo com políticas passadas. No caso do candidato vitorioso nas eleições, Fernando Henrique, a estratégia esteve centrada na apresentação de seu plano de governo e na análise de conjuntura, com especial ênfase na sua vinculação com o Plano Real.

Em termos gerais, os apelos do programa de Fernando Henrique foram os que mais se adequaram ao cenário das eleições. Como já apontado por alguns autores, o Plano Real cumpriu um papel central no processo de decisão de voto dos eleitores (Mendes \& Venturi, 1994). A 
análise do programa de Fernando Henrique revelou uma importante ênfase na avaliação da conjuntura, principalmente no que se refere ao novo plano econômico. Fernando Henrique vinculou sua candidatura ao Real como criador do Plano e como o único capaz de dar continuidade a ele. Este impacto do Plano no processo eleitoral foi potencializado pelo clima de otimismo e confiança presente no cenário, construído tanto na cobertura jornalística como nas telenovelas. Como vimos, os apelos

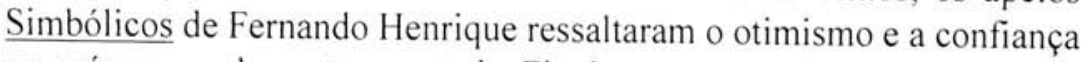
no país como elementos centrais. Finalmente, os apelos Atributos Pessoais do candidato destacaram o seu preparo e conhecimento. Desta forma Fernando Henrique se adequava à importância dada pelo cenário ao candidato preparado e com conhecimento.

A ênfase de Fernando Henrique no seu plano de governo e no Plano Real contrasta com a estratégia dos demais candidatos. No caso dos candidatos de "centro-esquerda", Lula e Brizola, a ênfase no apelo Propaganda Negativa se chocava com o clima de otimismo e confiança. A rejeição do Plano Real por parte do programa de Brizola e a atitude ambígua do programa de Lula, com predominância de críticas abertas, também contrastava com os elementos constitutivos do cenário. Estas candidaturas, principalmente a de Lula, encontraram obstáculos também na desqualificação dos ideais e lideranças de esquerda.

Os apelos do programa de Fernando Henrique foram os mais sintonizados com o cenário de longo prazo construído nos programas de maior audiência da televisão, o que, segundo a perspectiva teórica do CR-P, é uma condição importante para o êxito eleitoral dos candidatos. As observações aqui desenvolvidas sobre a hipótese eleitoral do CR-P foram apresentadas como uma contribuição no sentido da contextualização da propaganda política, ressaltado a disputa pela hegemonia que, nas sociedades mais complexas, tem na televisão uma arena fundamental. Estudos mais sistemáticos e abrangentes são necessários para a comprovação da hipótese sobre a relação entre a propaganda política e o cenário construído a longo prazo pelos mídia, particularmente pela televisão. Também importante é investigar em que medida a propaganda política constitui e/ou transforma o cenário dominante. Muito há por se fazer na investigação destas questões fundamentais, mas ainda negligenciadas, do processo político contemporâneo.

\section{Notas}


' Não foram analisados os programas dos candidatos que alcançaram menos de $1 \%$ de votos (Carlos Gomes, do PRN e Hernani Fortuna, do PSC).

${ }^{2}$ É importante notar, todavia, que existem grandes diferenças na audiência do HEG nas nove regiões metropolitanas: bem inferior em Porto Alegre e nas maiores áreas urbanas (Rio e São Paulo) e bem superior no Distrito Federal e na região nordeste (Recife e Salvador).

${ }^{3}$ O estudo de Carvalho (1994), por exemplo, foi criticado por não considerar os limites e potencialidade da televisão em geral, não concedendo um tratamento teórico adequado ao horário eleitoral (Albuquerque, 1996, p. 123).

${ }^{4}$ Um tipo de enfoque similar foi desenvolvido no caso da propaganda política nas eleições municipais de 1996 (Aldé \& Dias, 1997).

${ }^{5}$ Sobre a importância do Plano Real nestas eleições, ver Mendes e Venturi, 1994.

${ }^{6}$ Quando as "vinhetas" tratavam de temas relacionados com outros apelos, como, por exemplo, atributos pessoais, valores simbólicos etc, foram classificadas nestas outras categorias.

${ }^{7} \mathrm{Em}$ diversos momentos, as mensagens dos programas incluíam mais de um tipo de apelo. Optamos, todavia, por uma interpretação qualitativa sobre o apelo que predominava, classificando o trecho do programa nessa categoria.

${ }^{8}$ Apenas um programa não foi gravado e analisado devido a problemas técnicos (21de agosto).

${ }^{9}$ A pesquisa inclui apenas o HEG veiculado no horário nobre, não considerando os programas matutinos por serem em sua maioria meras repetições e terem uma audiência menor que o noturno.

\section{Bibliografia}

ALBUQUERQUE, Afonso de (1995a). "O horário gratuito da propaganda eleitoral e os spots políticos: particularidades do audio- visual brasileiro". In José Luiz Braga, Sérgio Porto \& Antônio Fausto Neto (Orgs.), A encenação dos sentidos: midia, cultura e política. Rio de Janeiro: Diadorim, p. 97-110.

ALBUQUERQUE, Afonso de (1995b). "Política versus televisão: o Horário Gratuito na campanha presidencial de 1994". Comunica- 
ção \& Política, Nova Série, v. 1, n. 3, abril-julho, p. 49-54.

ALBUQUERQUE, Afonso de (1996). A batalha pela presidencia: o horário gratuito de propaganda eleitoral na campanha de 1989. Tese de Doutorado em Comunicação e Cultura, UFRJ.

ALDÉ, Alessandra \& DIAS, Heloisa (1997). Intervalo surpresa: spots eleitorais na campanha municipal de 1996. Trabalho apresentado na VI Reunião Anual da Associação Nacional de Pós-Graduação em Comunicação (COMPÓS), São Paulo.

ALMEIDA, Jorge (1997). "Esquerda, pesquisas e marketing politico". Teoria \& Debate, n. 34, março-maio, p. 12-15.

BARTELS, Larry (1993). "Message received: the political impact of media exposure". American Political Science Review, v. 87, p. 267-285.

CARNEIRO, Leandro P. \& SCHMITT, Rogério A. (1995). "Eleições casadas, resultados nem sempre solteiros: campanhas proporcionais e imagem partidária no horário gratuito de propaganda eleitoral". Opinião Pública, v. III, n. 1, p. 45-58.

CARVALHO, Fátima L. (1994). O centro do labirinto: um estudo sobre a competição eleitoral na TV. Dissertação de Mestrado em Ciência Politica, IUPERJ.

CHRISTIANS, Clifford \& CAREY, James (1981). "The logic and aims of qualitative research". In Guido Stempel III \& Bruce Westley (Eds.), Research Methodos in Mass Communication. Englewood Cliffs: Prentice-Hall, p. 342-362.

DEL VALLE, Ruth (1995). A democracia petista nas telas da televisão brasileira (1980-1994). Dissertação de Mestrado em Ciência Política, Universidade de Brasília.

DUARTE, Celina Rabello (1980). "A Lei Falcão: antecedentes e impacto". In Bolivar Lamounier (Org.), Voto de desconfiança. São Paulo: Vozes, p. 173-216.

FABRÍCIO, Gustavo \& MACIEL, Evelin (1994). A construção do "ce- 
nário de representação da política" no Jornal Nacional. Trabalho apresentado no I Encontro Nacional de Estudos Sobre Comunicação e Política, Salvador/BA, 14 a 16 de dezembro.

GOMES, Wilson (1994). "Propaganda política, ética e democracia". In Heloisa Matos (Org.), Midia, eleições e democracia. São Paulo: Scritta, p. 53-90.

JORGE, Vladimyr Lombardo (1995). A eleição presidencial de 1994 e os meios de comunicação de massa. Uma análise da propaganda eleitoral gratuita de Fernando Henrique Cardoso e Luís Inácio Lula da Silva na televisão. Dissertação de Mestrado em Ciência Política, IUPERJ.

JOSLYN, Richard A. (1990). "Election campaigns as occasions for civic culture". In David L. Swanson e Dan Nimmo (Eds.), New Directions in Political Communication. Newbury Park: Sage, p. 86-119.

KUSCHNIR, Karina (1995). Notas para uma análise do horário eleitoral gratuito de televisão. Trabalho apresentado ao XIX Encontro Anual da ANPOCS, Caxambu/MG.

LIMA, Venício A. de (1994a). "Propaganda política no rádio e na televisão". In Heloisa Matos (Org.), Mídia, eleições e democracia. São Paulo: Scritta, p. 191-205.

LIMA, Venício A. de (1994b). "Televisão e poder: a hipótese do cenário de representação da política, CR-P”. Comunicação \& Política, Nova Série, v. 1, n. 1, agosto-novembro, p. 5-22.

LIMA, Venício A. de (1996). "Os mídia e o cenário de representação da política". Lua Nova, n. 38, p. 239-271.

LIMA JR., Olavo Brasil de (1993). "Participação e marginalidade eleitoral: racionalidade e determinismo social". In Luis Pedone (Org.), Sistemas eleitorais e processos politicos comparados. Brasília: OEA/UnB, p. 229-240.

MELO, Luciana \& OLIVEIRA, Renata (1994). A construção do CR-P na novela "Pátria Minha": eleições 1994. Trabalho apresentado 
no I Encontro Nacional de Estudos Sobre Comunicação e Política, Salvador/BA, 14 a 16 de dezembro.

MENDES, Antônio Manuel T. e VENTURI, Gustavo (1994). "Eleição presidencial: o Plano Real na sucessão de Itamar Franco". Opinião pública, v. II, n. 2, dezembro, p. 39-48.

MIGUEL, Luis Felipe (1997). "Mídia e discurso político nas eleições presidenciais de 1994". Comunicação \& Política, Nova Série, v. IV, n. 1, janeiro-abril, p. 80-96.

PATTERSON, Thomas \& McCLURE, Robert (1976). The unseeing eye: the myth of television power in national politics. New York: G.P. Putnam's Sons.

PORTO, Mauro Pereira (1995). "Telenovelas e política: o CR-P da eleição presidencial de 1994", Comunicação \& Política, Nova Série, Vol. 1, n. 3, abril-julho, pp. 55-76.

SOARES, Murilo (1996). Os significados do voto. Trabalho apresentado no V Encontro Anual da COMPÓS, São Paulo/SP, maio.

STEMPEL III, Guido (1981). "Content analysis". In Guido Stempel III \& Bruce Westley (Eds.), Research Methodos in Mass Communication. Englewood Cliffs: Prentice-Hall, p. 119-130.

STRAUBHAAR, Joseph; OLSEN, Organ \& NUNES, Maria Cavaliari (1993). "The Brazilian case: influencing the voter". In Thomas Skidmore (Ed.), Television, politics and the transition to democracy in Latin America. Baltimore: The Johns Hopkins University Press, p. 118-136.

VIEIRA, Nilcilene Alves (1993). A regulamentação da propaganda eleitoral no Brasil 1985-1989: o horário eleitoral gratuito em debate. Dissertação de Mestrado, Faculdade de Comunicação, Universidade de Brasília.

ZHAO, Xinshu \& CHAFFEE, Steven (1995). "Campaign advertisements versus television news as sources of political issue information". Public Opinion Quaterly, v. 59, p. 41-65. 